\title{
A comparative analysis of the diagnostic performances of four clinical probability models for acute pulmonary embolism in a sub-Saharan African population: a cross- sectional study
}

Agnès Esiéné ${ }^{1,2}$, Joel Noutakdie Tochie ${ }^{1 *}$ D , Junette Arlette Mbengono Metogo ${ }^{1,3}$, Paul Owono Etoundi ${ }^{1,2}$ and Jacqueline Ze Minkande ${ }^{1,4}$

\begin{abstract}
Background: The diagnosis of acute pulmonary embolism (PE) is one of the most challenging in emergency settings where prompt and accurate decisions need to be taken for life-saving purposes. Here, the assessment of the clinical probability of PE is a paramount step in its diagnosis. Although clinical probability models (CPM) for PE are routinely used in emergency departments (EDs) of low-resource settings, few studies have cited their diagnostic performances in sub-Saharan Africa (SSA). We aimed to comparatively assess the accuracy of four CPM in the diagnosis of acute PE in sub-Saharan Africans.

Methods: We carried out a cross-sectional study to compare the sensitivity, specificity, positive and negative predictive values and accuracy of four CPM namely; the Wells, simplified Wells, revised Geneva and the simplified revised Geneva (SRG) Scores to computed tomography pulmonary angiography (CTPA) in all adults patients with suspected PE admitted to the EDs of the Gynaeco-obstetric and Paediatric Hospital of Yaoundé and the Yaoundé Central Hospital in Cameroon between January 1, 2017 and April 30, 2018.

Results: In total, we enrolled 30 patients with clinical suspicion of acute PE. PE was confirmed on CTPA in 16 $(53.3 \%)$ cases. Their mean age was $53.7 \pm 15.5$ years and $36.7 \%$ were males. All four scores had a diagnostic performance superior to $50 \%$ in all criteria assessed. The simplified Wells score had the highest sensitivity (62.5\%) followed by the Wells score (56.3\%). The SRG score had the highest specificity (71.4\%). The score with highest PPV was the SRG score (66.7\%) and that with the highest NPV was the Wells score (56.3\%). Overall the models with the highest accuracies were the Wells and SRG scores (60\% for each).

Conclusion: All CPM had a suboptimal diagnostic performance, perhaps highlighting the need of a more optimal CPM for acute PE in SSA. However, the Wells and the SRG scores appeared to be most accurate than the other two scores in the ED. Hence, both or either of them may be used in first intention to predict PE and guide which ED patients should undergo further investigations in an emergency SSA setting.
\end{abstract}

Keywords: Pulmonary embolism, Wells score, Simplified wells score, Revised Geneva score, Simplified revised Geneva score, Emergency depatment, Sub-Saharan African

\footnotetext{
* Correspondence: joeltochie@gmail.com

${ }^{1}$ Department of Anesthesiology and Critical Care, Faculty of Medicine and

Biomedical Sciences, University of Yaoundé I, Yaoundé, Cameroon

Full list of author information is available at the end of the article
}

(c) The Author(s). 2019 Open Access This article is distributed under the terms of the Creative Commons Attribution 4.0 International License (http://creativecommons.org/licenses/by/4.0/), which permits unrestricted use, distribution, and reproduction in any medium, provided you give appropriate credit to the original author(s) and the source, provide a link to the Creative Commons license, and indicate if changes were made. The Creative Commons Public Domain Dedication waiver (http://creativecommons.org/publicdomain/zero/1.0/) applies to the data made available in this article, unless otherwise stated. 


\section{Background}

Pulmonary embolism (PE) is the most life threatening complication of venous thromboembolism with a 30-day mortality rate of $14-44 \%$ [1-4] and a one-year mortality rate of $21-52 \%[2,4,5]$. It poses a significant diagnostic challenge in acute medicine due to the lack of pathognomic symptoms and signs [6]. While fatal PE may be the first presentation of venous thromboembolism [7], the diagnosis of PE could be easily overlooked $[8,9]$ till a confirming autopsy diagnosis [7]. As a result, physicians have developed a low threshold for clinical suspicion and diagnostic testings [10]. Nonetheless, only $10-15 \%$ of patients suspected to have acute PE would be confirmed during further investigations [11]. It is worth to mention that, over-testing results in undue expenditures, and complications such as contrastinduced allergic reactions, contrast-induced nephropathy [12] or radiation-induced solid tumors [13] from multidetector computed tomography pulmonary angiography (CTPA), currently considered the gold standard diagnostic test for PE [14]. Attempting to remedy the problem of unnecessary testing, several clinical probability models (CPM), among which the most widely used are the Wells [15], simplified Wells [16], Revised Geneva [17] and Simplified Revised Geneva [18] scores, were put forth to guide the choice of diagnostic testing depending on the assessed PE probability stratified as low, moderate or high [14]. Guidelines recommend their use combined with D-dimer measurement to avert patients with a low PE probability from undergoing further investigations, without jeopardizing their safety [14]. This diagnostic approach has been reported to decrease the number of undue CTPA by onethird, with just $1-2 \%$ missed patients in the group of low probability [19]. This may be of tremendous economic importance in poor-resource emergency department (EDs) of sub-Saharan Africa (SSA) where multi-detector CTPA is quiet scarce and expensive for the majority of the population [20].

Worldwide, primary healthcare centers and EDs are the first to manage of patients with suspicion of acute PE [21]. Here, a rapid accurate diagnosis of PE is crucial. As aforementioned, diagnosing acute PE commences with probability stratification through CPM to preclude patients with a low PE probability from undue further testings $[14,21]$. Although widely externally validated in of European countries and the U.S.A where there were derived [21, 22], the lack of evidence on the diagnostic performances of these CPM from SSA makes their applicability of this region a topic of on-going debates [23]. CPM designed in a particular setting perform less in another geographical area [24-27] due to differences in the prevalence of disease and in physicians' experience of suspected cases [24]. As such, generalizing the validity of PE's predictive models to SSA without prior scientific evidence, may be inappropriate given that the black race has a $30-60 \%$ increase in the incidence of PE [28-30], as well as a $30 \%$ increase in PE-related mortality compared to other ethnicities [31]. Report from northern Africa have demonstrated the Pisa model, Wells score and Revised Geneva Score to be most accurate in clinical prediction of PE [32]. Studies conducted in western countries, show that the Wells score and Revised Geneva Score are most accurate in the prediction of PE in the ED [33]. To the best of our knowledge, only one SSA study carried out in a non-emergency department, a cardiology unit in Burkina Faso showed the Wells and Revised Geneva Scores to have a moderate clinical probability in predicting PE [23]. Hence, we aimed to comparatively evaluate the diagnostic accuracy of the four routinely used CPM in the diagnostic approach of acute PE in SSA. We hypothesized that Wells score could best accurately predict PE in an ED of SSA.

\section{Methods}

The methods were described in a study protocol by the same authors [34].

\section{Study design and setting}

This was a cross-sectional multicenter study carried out in the EDs of the following hospitals: the Yaoundé Gynaecoobstetric and Paediatric Hospital and the Yaoundé Central Hospital between the 1st January 2017 and 30th April 2018. Both hospital are referral and University Teaching hospitals in the capital city of Cameroon, Yaoundé. The Yaoundé Gynaeco-obstetric and Paediatric Hospital is specialized in the treatment of mother and child diseases, but also critical pathologies of the pregnant mother and child. The unit is managed by a Professor in Emergency Medicine and Anaesthesiology-Critical Care Medicine, three consultant Anaesthesiologists-Intensivists and 16 nurses. The Yaoundé Central Hospital is a referral hospital for all adult male and female diseases. To this end, it has a ED for both medical and surgical critical pathologies. The unit is managed by two Professors in Anaesthesiology-Critical Care Medicine, two consultant Anaesthesiologists-Intensivists, 14 nurses and averagely four resident physicians in Anaesthesiology and Critical Care Medicine. Both EDs have anticoagulants but lack thrombolytic drugs such as streptokinase.

\section{Patient eligibility criteria}

We prospectively enrolled all consenting consecutive patients aged beyond 15 years who presented with clinical suspicion of PE to these two EDs. A case of clinical suspicion was defined as any patient presenting with sudden dyspnoea, chest pain, haemoptysis or syncope. All patients presenting with chest pain and syncope underwent a 12 led electrocardiogram (E.C.G) to rule out or rule in an acute coronary syndrome or heart block at the ED. Those with ECG signs of acute coronary syndrome or heart block were excluded and offered treatment accordingly. We also 
excluded those who refused to consent, those who did not undergo computed tomography pulmonary angiography to rule in or rule out PE despite clinical suspicion, patients with contraindications to computed tomography pulmonary angiography (haemodynamic instability, dehydration, altered renal function) and all patients with a diagnosis of thromboembolic disease documented prior to admission.

\section{Sampling method}

Assuming a power of 20\%, a prevalence rate of PE of $39.7 \%$ in Douala, Cameroon [35], the SCHULZ and GRIMES formula was used to obtain a minimum size of our sample of 10 subjects per group. The sampling method was exhaustive and consecutive.

\section{Definition of clinical probability scores}

These fours scores, called clinical prediction scores for PE can be defined as pre-test probability models designed to stratify patients with suspected PE into three distinct groups (low-, intermediate- and high-risk) that correspond to an increasing actual prevalence of CTPA confirmed PE [14]. The Wells score (Table 1) [16] is the most used score in high-income settings where it has been validated extensively using both a three-stratification (low, moderate, or high clinical probability of $\mathrm{PE}$ ) and a two-stratification (PE likely or unlikely) approach [36]. The Wells score is simple to compute and is based on bedside clinical date that is

Table 1 The original Wells score and simplified Wells score for pulmonary embolism

\begin{tabular}{|c|c|c|}
\hline Predictive variables & $\begin{array}{l}\text { Original } \\
\text { Wells score }\end{array}$ & $\begin{array}{l}\text { Simplified } \\
\text { Wells score }\end{array}$ \\
\hline Previous PE or DVT & 1.5 & 1 \\
\hline Heart rate $>100$ bpm & 1.5 & 1 \\
\hline Recent surgery or immobilization & 1.5 & 1 \\
\hline Clinical signs of DVT & 3 & 1 \\
\hline $\begin{array}{l}\text { Alternative diagnosis less likely } \\
\text { than PE }\end{array}$ & 3 & 1 \\
\hline Haemoptysis & 1 & 1 \\
\hline \multirow[t]{8}{*}{ Cancer } & 1 & 1 \\
\hline & $\begin{array}{l}\text { Pretest } \\
\text { probability; }\end{array}$ & $\begin{array}{l}\text { Pretest } \\
\text { probability; }\end{array}$ \\
\hline & 0-1: low & $\begin{array}{l}\leq 1: \text { PE unlikely } \\
\text { (low) }\end{array}$ \\
\hline & 2-6: moderate & $\begin{array}{l}>1 \text { : PE likely } \\
\text { (high) }\end{array}$ \\
\hline & $\geq 7:$ high & \\
\hline & $\begin{array}{l}\text { Dichotomized } \\
\text { score: }\end{array}$ & \\
\hline & $\begin{array}{l}\leq 4: \text { PE unlikely } \\
\text { (low) }\end{array}$ & \\
\hline & $\begin{array}{l}>4 \text { : PE likely } \\
\text { (high) }\end{array}$ & \\
\hline
\end{tabular}

DVT Deep venous thrombosis, PE Pulmonary embolism easy to obtain. On the other hand, the weight of one subjective item ('alternative diagnosis less likely than PE') may decrease the inter-observer reproducibility of this score $[37,38]$. Both the Wells and the Revised Geneva scores (Table 2) were simplified CPM designed in an attempt to increase their universal adoption and widespread clinical applicability (Table 2) [39, 40]. These simplified versions have equally ben externally validated high-income countries $[41,42]$.

\section{Study procedure}

We approached all consecutive patients admitted for clinical suspicion of PE in order to obtain an informed consent. Using a pilot tested interview administered questionnaire, these were assessed for PE clinically probability using four clinical scores externally validated in high-income countries, before any other test to avoid bias; the original Wells score, the simplified Wells score, the Revised Geneva score and the SRG Score.

Patients were considered to have chronic heart failure, cancer, history of previous DVT or PE, or chronic pulmonary disease if these conditions were known prior to

Table 2 The revised Geneva score and simplified revised Geneva score for pulmonary embolism

\begin{tabular}{|c|c|c|}
\hline Predictive variables & $\begin{array}{l}\text { Revised } \\
\text { Geneva score }\end{array}$ & $\begin{array}{l}\text { Simplified Revised } \\
\text { Geneva score }\end{array}$ \\
\hline Age $>65$ years & 1 & 1 \\
\hline $\begin{array}{l}\text { Active malignancy (or considered } \\
\text { cure }<1 \text { year) }\end{array}$ & 2 & 1 \\
\hline $\begin{array}{l}\text { Recent surgery or fracture of the } \\
\text { lower limbs within } 1 \text { month }\end{array}$ & 2 & 1 \\
\hline Previous PE or DVT & 3 & 1 \\
\hline Haemoptysis & 2 & 1 \\
\hline Unilateral lower limb pain & 3 & 1 \\
\hline $\begin{array}{l}\text { Tenderness on lower limb deep } \\
\text { venous palpation and unilateral } \\
\text { oedema }\end{array}$ & 4 & 1 \\
\hline \multicolumn{3}{|l|}{ Heart rate } \\
\hline 75-94 bpm & 3 & 1 \\
\hline \multirow[t]{8}{*}{$\geq 95 \mathrm{bpm}$} & 5 & 2 \\
\hline & $\begin{array}{l}\text { Pretest } \\
\text { probability; }\end{array}$ & $\begin{array}{l}\text { Pretest } \\
\text { probability; }\end{array}$ \\
\hline & 0-3: low & $0-1$ : low \\
\hline & $\begin{array}{l}\text { 4-10: } \\
\text { moderate }\end{array}$ & 2-4: moderate \\
\hline & $\geq 11:$ high & $\geq 5$ : high \\
\hline & $\begin{array}{l}\text { Dichotomized } \\
\text { score: }\end{array}$ & $\begin{array}{l}\text { Dichotomized } \\
\text { score: }\end{array}$ \\
\hline & $\begin{array}{l}\text { 0-5: PE } \\
\text { unlikely (low) }\end{array}$ & $\begin{array}{l}\text { 0-2: PE unlikely } \\
\text { (low) }\end{array}$ \\
\hline & $\begin{array}{l}\geq 6: \text { PE likely } \\
\text { (high) }\end{array}$ & $\begin{array}{l}\geq 3: \text { PE likely } \\
\text { (high) }\end{array}$ \\
\hline
\end{tabular}

DVT Deep venous thrombosis, PE Pulmonary embolism 
admission. Recent surgery was defined as any surgical procedure performed within the last 4 weeks prior to the patient's admission. A prolonged journey was defined as one lasting at least 4 hours [43]. Questionnaires were completed and systematically reviewed for completeness before proceeding to further diagnostic testing.

\section{Diagnostic testing and assessment of potential sources of} bias

After assessment of the clinical prediction of PE, all patients with no contraindication for CTPA underwent this test as the reference diagnostic test. The diagnosis of PE was established by CTPA detection of an embolus in the pulmonary blood vessels. Radiologists performing the CTPA were blinded to the results of CPM.

\section{Data analyses}

Using CTPA as the reference diagnostic test, we compared the sensitivity, specificity, positive predictive value, negative predictive value and accuracy of each CPM. Sensitivity was defined by the proportion of patients with CTPA confirmed PE who had a PE likely probability. Specificity was the proportion of patients with CTPA unconfirmed PE who had a PE unlikely probability. The positive predictive value was the proportion of patients with a PE likely score who had CTPA confirmed PE.
The negative predictive value was the proportion of patients with PE unlikely probability who had an unconfirmed PE on CTPA. The accuracy of each CPM was the proportion of correct clinical assessments divided by the number of all assessments. Data was entered into EPI Info 3.5.1 statistical software and the threshold of statistical significance was set at 0.05 .

\section{Results}

\section{General characteristics of the study population}

We received 34 patients with clinical suspicion of PE. Three patients were excluded due to the diagnosis of acute coronary syndrome and one because he had contraindications (dehydration and a state of shock) for CTPA (Fig. 1). Hence, we enrolled 30 patients with clinical suspicion of PE seen at the ED. PE was confirmed on CTPA in 16 (53.3\%) cases. Their mean age was $53.7 \pm 15.5$ years (range: $32-87$ years). About one-third (36.7\%) were males, thus, a male to female ratio of 0.57 . Dyspnoea was the main reason for ED admission in 86.7\% of cases. Patients with confirmed PE and unconfirmed PE were comparable with regards to age, gender, symptoms and signs of PE (Table 3). Obesity was significantly associated with PE. Table 3 summarises the general characteristics of the study population.

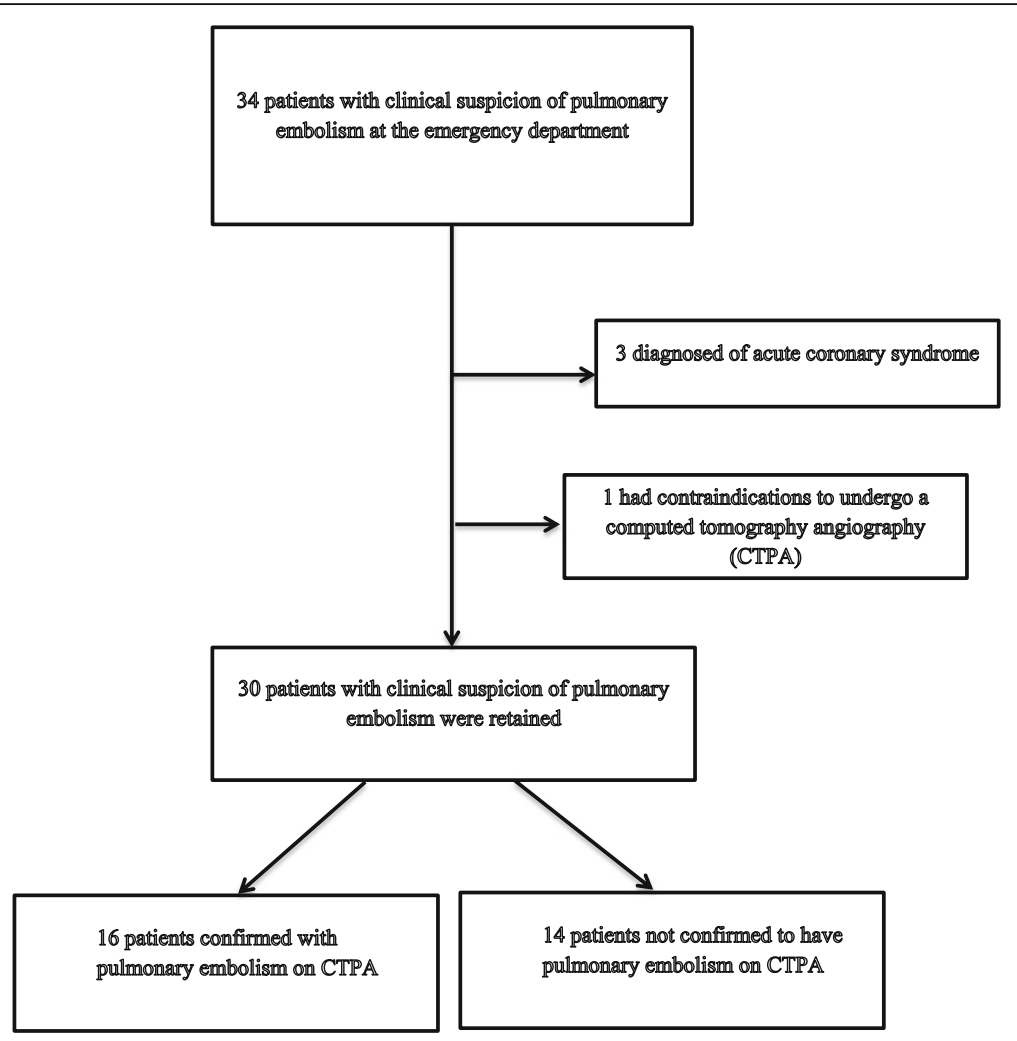

Fig. 1 Flow diagram of study selection 
Table 3 Socio-demographic and clinical characteristics

\begin{tabular}{|c|c|c|c|c|}
\hline Groups & $\begin{array}{l}\text { Number } \\
(\%) \\
(n=30)\end{array}$ & $\begin{array}{l}\text { PE } \\
\text { confirmed } \\
(n=16)\end{array}$ & $\begin{array}{l}\text { PE } \\
\text { unconfirmed } \\
(n=14)\end{array}$ & $P$ value \\
\hline \multicolumn{5}{|l|}{ Age } \\
\hline$<65$ & $23(76.7 \%)$ & 13 & 10 & 0.7431 \\
\hline $65-74$ & $4(13.3 \%)$ & 1 & 2 & \\
\hline $75-84$ & $3(10 \%)$ & 2 & 2 & \\
\hline Gender & & & & 0.3922 \\
\hline Male & $11(36.7 \%)$ & 7 & 4 & \\
\hline Female & 19 (63.3\%) & 9 & 10 & \\
\hline Occupation & & & & 0.8177 \\
\hline Employed & $23(76.7 \%)$ & 12 & 11 & \\
\hline Unemployed & 7 (24.3\%) & 4 & 3 & \\
\hline \multicolumn{5}{|l|}{ Reason for admission } \\
\hline Chest pain & $11(36.7 \%)$ & 7 & 4 & 0.3165 \\
\hline Dyspnoea & $26(86.7 \%)$ & 13 & 13 & 0.3524 \\
\hline Haemoptysis & $1(3.3 \%)$ & 0 & 1 & 0.4666 \\
\hline Syncope & $3(10 \%)$ & 2 & 1 & 0.5517 \\
\hline \multicolumn{5}{|l|}{ Risk factors } \\
\hline HIV & $5(16.7 \%)$ & 3 & 2 & 0.5670 \\
\hline Obesity & $4(13.3 \%)$ & 0 & 4 & 0.0365 \\
\hline Prolonged journey & 1 (3.3\%) & 1 & 0 & 0.5333 \\
\hline Recent surgery & $5(16.7 \%)$ & 3 & 2 & 0.5670 \\
\hline Active cancer & $2(6.7 \%)$ & 1 & 1 & 0.7241 \\
\hline $\begin{array}{l}\text { Past } \\
\text { thromboembolism }\end{array}$ & $2(6.7 \%)$ & 2 & 0 & 0.2758 \\
\hline \multicolumn{5}{|l|}{ Clinical signs } \\
\hline Homans sign & $9(30 \%)$ & 7 & 2 & 0.0861 \\
\hline Pulse $\geq 100$ & $15(50 \%)$ & 10 & 5 & 0.1361 \\
\hline Hypotension & $4(13.3 \%)$ & 3 & 1 & 0.3677 \\
\hline
\end{tabular}

Table 4 shows the stratification of patients according to the clinical probability of PE and the frequency of PE in three clinical probability categories (low, moderate and high) for each prediction model. The proportions of patients categorized as having low, moderate, or high probability were, respectively: 20,67 , and $13 \%$, for the Wells model; 33, 63, and 4\%, for the Revised Geneva model; 40, 53, and 7\% for the Simplified Revised Geneva model. The frequencies of confirmed PE in the low, intermediate, and high probability categories were, respectively: 33,55 , and $75 \%$ for the Wells model; 50,53 , and $100 \%$ for the Revised Geneva model; 50, 62.5, and 0\% for the Simplified Revised Geneva model. Table 5 summarizes the diagnostic performance of all four scores.

\section{Discussion}

This study aimed to determine the diagnostic performances of four bedsides CPM for PE in an emergency setting in SSA. Overall, the models with the highest accuracies were the Well and SRG scores (56.3\%).

Two previous reports, the Prospective Investigative Study of Acute Pulmonary Embolism Diagnosis [44] and Prospective Investigation of Pulmonary Embolism Diagnosis [45], emphasized the importance of pre-test for patients with suspected PE. As the aforementioned studies had drawn backs due to standardization, Wells et al. designed a more standardized clinical scoring system in which 66.7, 20.5 and $3.6 \%$ of patients with a high, intermediate and low-probability score were diagnosed with PE [16]. Table 6 compares the different clinical probability values obtained with the Wells score from other studies against the present study. Likewise, the Revised Geneva score designed in 2006 showed that 74, 28 and $8 \%$ of the ED patients in the high-, intermediate-and the low-probability group had PE [17]. By contrast, using the Revised Geneva score in the present study, we found that 100, 53 and 50\% patients with high, intermediate and low-probabilities were confirmed to have PE on CTPA. In a similar study done by Washsh et al. to compare seven CPM (original Geneva score, revised Geneva score, simplified Geneva score, Wells score, simplified Wells score, simplified Charlotte rule, Pisa model) for PE in a chest department in Egypt [32], like in our series, the simplified Wells score equally stood as the scoring system with the highest sensitivity ( $92 \%$ vs. $62.5 \%$ ). In a study conducted by Kim et al. [46] in the ED, the simplified Wells score had a sensitivity, specificity, PPV and NPV of 4.4, 98.6, 14.3 and $95.0 \%$. By contrast we obtained values of $62.5,50,58.8$ and $53.8 \%$ respectively for the same score. We found a sensitivity, specificity, NPV and PPV for the simplified revised Geneva score of 50, 71.4, 66.7 and 55.5\% respectively, contrarily to Kim et al. [46] who obtained 74, 35, 6, and 96\%, respectively for sensitivity, specificity, NPV and PPV.

Table 4 Proportion of patients and frequency of pulmonary embolism in the 3 clinical probability categories according to each prediction model

\begin{tabular}{|c|c|c|c|c|c|c|}
\hline \multirow{2}{*}{$\begin{array}{l}\text { Clinical } \\
\text { Probability }\end{array}$} & \multicolumn{2}{|l|}{ Wells score } & \multicolumn{2}{|c|}{ Revised Geneva score } & \multicolumn{2}{|c|}{ Simplified Revised Geneva score } \\
\hline & $\begin{array}{l}\text { Patients } \\
N=30(\%)\end{array}$ & $\begin{array}{l}\text { Patients } \\
\text { with PE (\%) }\end{array}$ & $\begin{array}{l}\text { Patients } \\
N=30(\%)\end{array}$ & $\begin{array}{l}\text { Patients } \\
\text { with PE (\%) }\end{array}$ & $\begin{array}{l}\text { Patients } \\
N=30(\%)\end{array}$ & $\begin{array}{l}\text { Patients } \\
\text { with PE (\%) }\end{array}$ \\
\hline Low & $6(20 \%)$ & $2(33 \%)$ & $10(33 \%)$ & $5(50 \%)$ & $12(40 \%)$ & $6(50 \%)$ \\
\hline Moderate & $20(67 \%)$ & $11(55 \%)$ & $19(63 \%)$ & $10(53 \%)$ & $16(53 \%)$ & $10(62.5 \%)$ \\
\hline High & $4(13 \%)$ & $3(75 \%)$ & 1 (4\%) & 1 (100\%) & $2(7 \%)$ & 00 \\
\hline
\end{tabular}


Table 5 Summary of the diagnostic performances of all four clinical probability models

\begin{tabular}{|c|c|c|c|c|c|}
\hline Models & $\begin{array}{l}\text { Sensitivity (\%) } \\
(95 \% \text { Cl) }\end{array}$ & $\begin{array}{l}\text { Specificity (\%) } \\
(95 \% \text { Cl) }\end{array}$ & $\begin{array}{l}\text { Positive } \\
\text { Predictive } \\
\text { Value (\%) } \\
(95 \% \mathrm{Cl})\end{array}$ & $\begin{array}{l}\text { Negative } \\
\text { Predictive } \\
\text { Value (\%) } \\
(95 \% \text { Cl) }\end{array}$ & $\begin{array}{l}\text { Accuracy } \\
(95 \% \text { Cl) }\end{array}$ \\
\hline Wells score & $56.3(29.8-80.25)$ & $64.3(35.14-87.24)$ & $64.3(44.1-71.6)$ & $56.3(39.47-71.72)$ & $60(40 .-77.3)$ \\
\hline Simplified Wells score & $62.5(35.43-84.8)$ & $50(23.04-76.96)$ & $58.8(42.8-73.18)$ & $53.8(33.91-72.62)$ & $37.43(37.43-74.54)$ \\
\hline Revised Geneva score & $50(24.65-75.35)$ & $64.3(35.14-87.24)$ & $61.5(40.45-79.03)$ & $52.9(37.55-67.79)$ & $56.67(37.43-74.54)$ \\
\hline Simplified Revised Geneva score & $50(24.65-75.35)$ & $71.4(41.90-91.61)$ & $66.7(43.31-83.96)$ & $55.5(40.89-69.31)$ & $60(40.60-77.34)$ \\
\hline
\end{tabular}

From our perspective, apart from being the models with the highest accuracy (60\%), the Wells score and SRG score both have the advantage of being purely clinical bedside sores and do not require arterial blood gas sample to be performed compared to more sophisticated scores [17]. The drawback of the Wells score is the "alternate diagnosis less likely than PE" parameter, which adds some degree of subjectivity to an otherwise objective model [47] and, as such, it can hardly be standardized [48]. To overcome this shortcoming of the Wells score, a fully standardized clinical model called the Geneva score, exclusively based on objective parameters was developed [49] and later revised and simplified into the revised Geneva score [17] and the SRG score [40]. Nevertheless, in our series, both the Wells score and the SRG score were found to be the two best scoring systems, with similar accuracy of $60 \%$ for ED patients with suspected PE. This finding concurs with that of a recent systematic review which found both model to be comparable in predicting PE [50]. Using the Wells score in our study, the highest proportion of patients (13\%) were categorized as having a high clinical probability score and up to $75 \%$ of them had a confirmed CTPA PE diagnosis. The frequency of the PE in the low probability category was somewhat higher than that originally reported by Wells [15]. This may be attributed to the higher prevalence of PE in the present study as compared to Wells' study. Hence, the Wells score is better suited to rule out rather than to rule in the diagnosis of $\mathrm{PE}$, and its performance is likely to be better in a clinical setting where the prevalence of $\mathrm{PE}$ is expected to be low [16]. Also, the superiority of the SRG score in our study over the simplified Wells score and the Revised Geneva score may be explained by fully standardized criteria itself and Geneva score-specific variables such as "age $>65$ years" and "surgery or fracture within 1 month," that are absent in the simplified Wells score.

We acknowledge some limitations of our study; firstly its small sample size $(n=30)$, given that simulation studies suggest a minimum of about 100 participants with the outcome of interest (PE) for robust validation studies. However, $\mathrm{PE}$ is a rare or often underdiagnosed pathology in Africa, whose prevalence has been recently reported to be low as $0.14 \%$ in a systematic review [51]. This may explain the reason for the small sample size in the present study. Secondly, the present study is not a full assessment of prediction models. We basically tested the point-score of four selected prediction models for PE at their recommended thresholds. We kept to this minimal approach, though we fully acknowledge that for full validation of the four models, we need to consider computing the probabilities from which the point-score were derived and validated, rather those probabilities as they are more accurate than the point-score. For instance, measures of discrimination such as c-statistic or area under the curve (AUC) and measures of calibration (calibration plots, Hosmer and Lemeshow statistics, observed/expected event rates, etc.) would have been more accurate. Furthermore, none of the scores portrayed a high diagnostic pre-probability for PE. Hence, it remains questionable whether these four scores are best suitable for the SSA population or is there a need for to develop a scoring system which can predict PE with high accuracy in EDs of SSA. The strengths of this study include: to the best of our knowledge, this is the first study to report the diagnostic performance of four routine bedside CPM for PE in an emergency setting in SSA.

\section{Conclusion}

Grosso modo, all four scores had a moderate diagnostic performance for PE in our setting. Overall, the wells and SRG scores appeared to be more accurate than the other

Table 6 Comparison of the diagnostic performances of the Wells score

\begin{tabular}{lllll}
\hline Clinical Probability & $\begin{array}{l}\text { At EDs in the } \\
\text { present study in Cameroon }\end{array}$ & $\begin{array}{l}\text { Original Wells } \\
\text { study [16] }\end{array}$ & $\begin{array}{l}\text { Washsh et al. in Cardiology } \\
\text { unit in Egypt [32] }\end{array}$ & $\begin{array}{l}\text { Miniati M et al. } \\
\text { in Italy }\end{array}$ \\
\hline Low & $33 \%$ & $3.6 \%$ & $0 \%$ & $12 \%$ \\
Moderate & $55 \%$ & $20.5 \%$ & $42.1 \%$ & $54 \%$ \\
High & $75 \%$ & $66.7 \%$ & $80 \%$ & $64 \%$
\end{tabular}

${ }^{\mathrm{a}}$ Miniati M, Bottai M, Monti S. Comparison of 3 clinical models for predicting the probability of pulmonary embolism, Medicine (Baltimore) 2005;84 (2):107-114 
two scores in the ED. Furthermore, the Wells score and the SRGS use only clinical variables, making them easy to use in EDs of Africa. Therefore, both or either scores may be used in first intention in patients seen at the ED with suspected of PE in our resource-limited settings like SSA. These findings may guide clinicians making informed decisions in predicting PE diagnosis and identification of patients at need of further testing or may be anticoagulants therapy in resource-challenged environments where CTPA is not always available or affordable to confirm the diagnosis of PE.

\section{Abbreviations}

CPM: Clinical probability model; CTPA: Computed tomography pulmonary angiography; ED: Emergency department; PE: Pulmonary embolism; SRG: Simplified Revised Geneva; SSA: Sub-Sahara Africa

\section{Acknowledgments}

We thank Dr. Frank Teddy Endomba and Dr. Emelinda Berinyuy for their help during the collection of data. The authors also thank all patients who partook in this study and wish to thank all the staff of the participating hospitals for their commitment in patient care. The abstract was presented at a conference.

\section{Authors' contributions}

AE and JNT: Study conception and design, acquisition of data, data analysis and interpretation, manuscript writing and critical revisions. JAMM, POE and JZM: critically revised the manuscript for intellectual content. All authors read and approved the final manuscript.

\section{Funding}

Not applicable

\section{Availability of data and materials}

The datasets used and/or analyzed during the current study are available from the corresponding author on reasonable request".

\section{Ethics approval and consent to participate}

The study was approved by the Institutional Review Board of the Faculty of Medicine and Biomedical Sciences, University of Yaoundé I, Yaoundé, Cameroon under the ethical clearance No 192/CIERSH/DM/2016.

Administrative authorizations were equally obtained from the administration of both hospitals involved prior to the beginning of the study. Written informed consent was obtained from all participants prior to inclusion into this study.

\section{Consent for publication}

Written informed consents were obtained from all participants prior to inclusion into this study.

\section{Competing interests}

The authors declare that they have no competing interests.

\begin{abstract}
Author details
${ }^{1}$ Department of Anesthesiology and Critical Care, Faculty of Medicine and Biomedical Sciences, University of Yaoundé I, Yaoundé, Cameroon. ${ }^{2}$ Department of Emergency Medicine, Anesthesiology and Critical Care, Yaounde Central Hospital, Yaoundé, Cameroon. ${ }^{3}$ Department of Emergency Medicine, Anesthesiology and Critical Care, Douala General Hospital, Douala, Cameroon. ${ }^{4}$ Department of Emergency Medicine, Anesthesiology and Critical Care, Gynaeco-Obstetrics and Paediatric Hospital, Yaoundé, Cameroon.
\end{abstract}

Received: 22 March 2019 Accepted: 19 December 2019 Published online: 27 December 2019

\section{References}

1. Mantilla CB, Horlocker TT, Schroeder DR, Berry DJ, Brown DL. Frequency of myocardial infarction, pulmonary embolism, deep venous thrombosis, and death following primary hip or knee arthroplasty. Anesthesiology. 2002; 96(5):1140-6.

2. Comfere TB, Sprung J, Case KA, Dye PT, Johnson JL, Hall BA, et al. Predictors of mortality following symptomatic pulmonary embolism in patients undergoing noncardiac surgery. Can J Anaesth. 2007;54(8):634-41.

3. Sakon M, Kakkar AK, Ikeda M, Sekimoto M, Nakamori S, Yano M, et al. Current status of pulmonary embolism in general surgery in Japan. Surg Today. 2004;34(10):805-10.

4. Heit JA, Silverstein MD, Mohr DN, Petterson TM, O'Fallon WM, Melton LJ 3rd. Predictors of survival after deep vein thrombosis and pulmonary embolism: a population-based, cohort study. Arch Intern Med. 1999;159(5):445-53.

5. Carson JL, Kelley MA, Duff A, Weg JG, Fulkerson WJ, Palevsky HI, et al. The clinical course of pulmonary embolism. N Engl J Med. 1992;326(19):1240-5.

6. Belohlavek J, Dytrych V, Linhart A. Pulmonary embolism, part I: Epidemiology, risk factors and risk stratification, pathophysiology, clinical presentation, diagnosis and nonthrombotic pulmonary embolism. Exp Clin Cardiol. 2013;18(2):129-38.

7. Lindblad B, Eriksson A, Bergqvist D. Autopsy-verified pulmonary embolism in a surgical department: analysis of the period from 1951 to. Br J Surg. 1988;1991:1849-52.

8. Barais M, Morio N, Cuzon Breton A, et al. "I can't fnd anything wrong: it must be a pulmonary embolism": diagnosing suspected pulmonary embolism in primary care, a qualitative study. PLoS One. 2014;9:e98112.

9. Schiff GD, Hasan O, Kim S, Abrams R, Cosby K, Lambert BL, et al. Diagnostic error in medicine: analysis of 583 physician-reported errors. Arch Intern Med. 2009;169(20):1881-7.

10. Wiener RS, Schwartz LM, Woloshin S. Time trends in pulmonary embolism in the United States: evidence of overdiagnosis. Arch Intern Med. 2011; 171(9):831-7.

11. Le Gal G, Bounameaux H. Diagnosing pulmonary embolism: running after the decreasing prevalence of cases among suspected patients. J Thromb Haemost. 2004:2(8):1244-6.

12. Mitchell AM, Kline JA. Contrast nephropathy following computed tomography angiography of the chest for pulmonary embolism in the emergency department. J Thromb Haemost. 2007;5(1):50-4.

13. Cochran ST, Bomyea K, Sayre JW. Trends in adverse events after IV administration of contrast media. Am J Roentgenol. 2001;176(6):1385-8.

14. Konstantinides SV, Torbicki A, Agnelli G, Danchin N, Fitzmaurice D, Galiè N, et al. 2014 ESC guidelines on the diagnosis and management of acute pulmonary embolism: the task force for the diagnosis and management of acute pulmonary embolism of the European Society of Cardiology (ESC)endorsed by the European Respiratory Society (ERS). Eur Heart J. 2014; 35(43):3033-73.

15. Wells PS, Ginsberg JS, Anderson DR, Kearon C, Gent M, Turpie AG, et al. Use of a clinical model for safe management of patients with suspected pulmonary embolism. Ann Intern Med. 1998;129(12):997-1005.

16. Wells PS, Anderson DR, Rodger M, Ginsberg JS, Kearon C, Gent M, et al. Derivation of a simple clinical model to categorize patient's probability of pulmonary embolism: increasing the model's utility with the SimpliRED ddimer. Thromb Haemost. 2000;83(3):416-20.

17. Le Gal G, Righini M, Roy PM, Sanchez O, Aujesky D, Bounameaux H, et al. Prediction of pulmonary embolism in the emergency department: the revised Geneva score. Ann Intern Med. 2006;144(3):165-71.

18. Kline JA, Nelson RD, Jackson RE, Courtney DM. Criteria for the safe use of $d$ dimer testing in emergency department patients with suspected pulmonary embolism: a multicenter US study. Ann Emerg Med. 2002;39(2):144-52.

19. Lucassen W, Geersing G-J, Erkens PMG, Reitsma JB, Moons KGM, Büller H, et al. Clinical decision rules for excluding pulmonary embolism: a metaanalysis. Ann Intern Med. 2011;155(7):448.

20. Tambe J, Moifo B, Fongang E, Guegang E, Juimo AG. Acute pulmonary embolism in the era of multi-detector CT: a reality in sub-Saharan Africa. BMC Med Imaging. 2012;12:31

21. Hendriksen JMT, Geersing GJ, Lucassen WAM, Erkens PMG, Stoffers HEJH, van Weert HCPM, et al. Diagnostic prediction models for suspected pulmonary embolism: systematic review and independent external validation in primary care. BMJ. 2015:351:h4438.

22. Righini $M$, Bounameaux $H$. External validation and comparison of recently described prediction rules for suspected pulmonary embolism. Curr Opin Pulm Med. 2004;10(5):345-9.

23. Samadoulougou AK, Millogo GRC, Seghda TAA, Yameogo RA, Damoue SN, Boro T, et al. Revised Geneva and Wells Clinicals scores performance in 
pulmonary embolism diagnosis in the University Hospital Yalgado Ouedraogo (Burkina Faso). Angéiologie. 2015;67:57-9.

24. Moons KGM, Kengne AP, Grobbee DE, Royston P, Vergouwe Y, Altman DG, et al. Risk prediction models: II. External validation, model updating, and impact assessment. Heart. 2012;98(9):691-8.

25. Altman DG, Royston P. What do we mean by validating a prognostic model? Stat Med. 2000;19(4):453-73.

26. Reilly BM, Evans AT. Translating clinical research into clinical practice: impact of using prediction rules to make decisions. Ann Intern Med. 2006;144(3):201-9.

27. Justice AC, Covinsky KE, Berlin JA. Assessing the generalizability of prognostic information. Ann Intern Med. 1999;130(6):515-24.

28. White $\mathrm{RH}$, Keenan $\mathrm{CR}$. Effects of race and ethnicity on the incidence of venous thromboembolism. Thromb Res. 2009;123(Suppl 4):S11-7.

29. Zakai N, Lutsey P, Folsom A, Cushman M. Black-white differences in venous thrombosis risk: the longitudinal investigation of thromboembolism etiology (LITE). In: Blood ASH annual meeting abstracts; 2010. p. 478

30. Schneider D, Lilienfeld DE, Wansoo IM. The epidemiology of pulmonary embolism: racial contrasts in incidence and in-hospital case fatality. J Natl Med Assoc. 2006;98(12):1967-72.

31. Ibrahim SA, Stone RA, Obrosky DS, Sartorius J, Fine MJ, Aujesky D. Racial differences in 30-day mortality for pulmonary embolism. Am J Public Health. 2006:96(12):2161-4.

32. Wahsh RAl, Agha MA. Clinical probability of pulmonary embolism: comparison of different scoring systems. Egypt J Chest Dis Tuberc. 2012;61:419-24.

33. Calisira C, Yavasa US, Ozkana IR, Alatasb R, Cevikc A, Ergunc N, Sahind F. Performance of the Wells and Revised Geneva scores for predicting pulmonary embolism. Eur J Emerg Med. 2009;16:49-52.

34. Esiéné A, Owono Etoundi P, Tochie JN, et al. Validity of four clinical prediction scores for pulmonary embolism in a sub-Saharan African setting: a protocol for a Cameroonian multicentre crosssectional study. BMJ Open. 2019;9:e031322. https://doi.org/10.1136/ bmjopen-2019-031322.

35. Kamdem F, Ngahane BHM, Hamadou B, Mongyui A, Doualla MS, Jingin AM, et al. Epidemiology, clinical presentations and in-hospital mortality of venous thromboembolism at the Douala General Hospital: across-sectional study in Cameroon, sub-Saharan Africa. World J Cardiovasc Dis. 2018:8:123-32.

36. Wells PS, Anderson DR, Rodger M, Stiell I, Dreyer JF, Barnes D, Forgie M, Kovacs G, Ward J, Kovacs MJ. Excluding pulmonary embolism at the bedside without diagnostic imaging: management of patients with suspected pulmonary embolism presenting to the emergency department by using a simple clinical model and d-dimer. Ann Intern Med. 2001;135(2):98-107.

37. Rodger MA, Maser E, Stiell I, Howley HE, Wells PS. The interobserver reliability of pretest probability assessment in patients with suspected pulmonary embolism. Thromb Res. 2005;116(2):101-7.

38. Wolf SJ, McCubbin TR, Feldhaus KM, Faragher JP, Adcock DM. Prospective validation of Wells criteria in the evaluation of patients with suspected pulmonary embolism. Ann Emerg Med. 2004;44(5):503-10.

39. Gibson NS, Sohne M, Kruip MJ, Tick LW, Gerdes VE, Bossuyt PM, Wells PS, Büller HR. Further validation and simplification of the Wells clinical decision rule in pulmonary embolism. Thromb Haemost. 2008:99(1): 229-34.

40. Klok FA, Mos IC, Nijkeuter M, Righini M, Perrier A, Le Gal G, et al Simplification of the revised Geneva score for assessing clinical probability of pulmonary embolism. Arch Intern Med. 2008;168(19):2131-6.

41. Douma RA, Gibson NS, Gerdes VE, Buller HR, Wells PS, Perrier A, Le Gal G. Validity and clinical utility of the simplified Wells rule for assessing clinical probability for the exclusion of pulmonary embolism. Thromb Haemost. 2009;101(1):197-200.

42. Douma RA, Mos IC, Erkens PM, Nizet TA, Durian MF, Hovens MM, van Houten AA, Hofstee HM, Klok FA, ten Cate H, Ullmann EF, Büller HR, Kamphuisen PW, Huisman MV. Performance of 4 clinical decision rules in the diagnosticmanagement of acute pulmonary embolism: a prospective cohort study. Ann Intern Med. 2011;154(11):709-18.

43. Kuipers S, Cannegieter SC, Middeldrop S, Robyn L, Buller HR, Rosendaal FR. The absolute risk of venous thrombosis after air travel: a cohort study of 8755 employees of the international organisations. PLoS One. 2007;4(9):e290.

44. The PIOPED investigators. Value of the ventilation/perfusion scan in acute pulmonary embolism: results of the prospective investigation of pulmonary embolism diagnosis (PIOPED). JAMA. 1990;263:2753-9.
45. Miniati M, Pistolesi M, Marini C, Di Ricco G, Formichi B, Prediletto R, et al Value of perfusion lung scan in the diagnosis of pulmonary embolism: results of the prospective investigative study of acute pulmonary embolism diagnosis (PISA-PED). Am J Respir Crit Care Med. 1996;154:1387-93.

46. Kim Y-J, Choi D-H, Lee ES, Ryoo SM, Ahn S, Sohn CH, et al. Utility of the simplified Wells and revised Geneva scores to exclude pulmonary embolism in femur fracture patients. Am J Emerg Med. 2017. https://doi.org/10.1016/j. ajem.2017.03.023.

47. Langan CJ, Weingart S. New diagnostic and treatment modalities for pulmonary embolism: one path through the confusion. Mt Sinai J Med. 2006;73:528-41.

48. Klok FA, Zidane M, Djurabi RK, Nijkeuter M, Huisman MV. The physician's estimation 'alternative diagnosis is less likely than pulmonary embolism' in the Wells rule is dependent on the presence of other required items. Thromb Haemost. 2008:99:244-5.

49. Wicki J, Perneger TV, Junod AF, Bounameaux H, Perrier A. Assessing clinical probability of pulmonary embolism in the emergency ward. A simple score. Arch Intern Med. 2001;161:92-7.

50. Ceriani E, Combescure C, Le Gal G, Nendaz M, Perneger T, Bounameaux H, et al. Clinical prediction rules for pulmonary embolism: a systematic review and metaanalysis. J Thromb Haemost. 2010;8(5):957-70.

51. Danwang C, Temgoua MN, Agbor VN, Tankeu AT, Noubiap JJ. Epidemiology of venous thromboembolism in Africa: a systematic review. J Thromb Haemost. 2017;15:1770-81.

\section{Publisher's Note}

Springer Nature remains neutral with regard to jurisdictional claims in published maps and institutional affiliations.

Ready to submit your research? Choose BMC and benefit from:

- fast, convenient online submission

- thorough peer review by experienced researchers in your field

- rapid publication on acceptance

- support for research data, including large and complex data types

- gold Open Access which fosters wider collaboration and increased citations

- maximum visibility for your research: over $100 \mathrm{M}$ website views per year

At $\mathrm{BMC}$, research is always in progress.

Learn more biomedcentral.com/submissions 